\title{
ESTRATÉGIAS EXPOGRÁFICAS NA MOSTRA 29 PRÊMIO DESIGN DO MUSEU DA CASA BRASILEIRA: ENTRE A CONTEMPLAÇÃO E A CRÍTICA
}

\author{
Ana Paula França \\ Universidade Positivo \\ Universidade Federal do Paraná \\ anafranca@ufpr.br \\ Ronaldo de Oliveira Corrêa \\ Universidade Federal do Paraná \\ rcorrea@ufpr.br
}

Resumo: O Museu da Casa Brasileira promove anualmente exposição de design de curta duração atrelada ao Prêmio Design, originado em 1986. Contudo, identificou-se que as possibilidades materiais de tais realizações periódicas são pouco debatidas. Este artigo apresenta uma análise da mostra da 29a edição do evento, ocorrida entre 26 de novembro de 2015 e 31 de janeiro de 2016. Tem como objetivo contemplar as estratégias expográficas em jogo de modo exploratório-descritivo. As noções como "cultura pública" e "abordagem interocular", definidas pelo pesquisador antropólogo Arjun Appadurai, são articuladas para discutir sobre as potencialidades e limites de uma exposição de artefatos de design.

Palavras-chave: expografia; exposição de design; Prêmio Design Museu da Casa Brasileira.

\begin{abstract}
The Museu da Casa Brasileira promotes annually short term design exhibitions linked to the Design Awards, originated in 1986. However, it was noted that the material possibilities of such periodic endeavors are little discussed. This article presents an analysis of the 29th edition of the exhibition, that happened between November 26 of 2015 and January 31 of 2016. It's objetive is to contemplate the expographic strategies at stake in a exploratory-observatory manner. Notions such as "public culture" and "interocular approach", defined by the anthropologist Arjun Appadurai, are articulated so they discuss the potentiality and limits of an exposition of design artifacts.
\end{abstract}

Keywords: expography, design exhibition, Prêmio Design Museu da Casa Brasileira 


\section{INTRODUÇÃO}

Um objeto de design não é definido somente por uma metodologia de projeto ou por um processo de produção. A diferença entre um objeto qualquer e um artefato de design pode ser demarcada igualmente por chancelas institucionais que constroem modelos, valores e critérios, selecionando e hierarquizando diferentes produtos.

No Brasil, um circuito de prêmios, salões e bienais de design forma-se a partir do fim da década de 1980. A maioria dos eventos que compõem tal itinerário apresenta ao público projetos de design selecionados por meio de exposições de curta duração. Um dos eventos mais antigos é o Prêmio Design Museu da Casa Brasileira. Segundo a curadora e crítica Adélia Borges, este "tornou-se o referencial maior quando se fala do design de equipamentos para o habitat em nosso país" (...) retratando a trajetória do design contemporâneo brasileiro" (BORGES, 1996, p. 10).

Para concorrer ao prêmio, profissionais e empresas devem seguir à risca determinado procedimento de inscrição. O regulamento da 29a edição do evento (PRÊMIO DESIGN MCB, 2016) indica a necessidade de envio de imagens digitais e informações textuais sobre o objeto por meio de cadastramento online. Além disso, apresenta as categorias e os critérios de seleção como originalidade, concepção formal e inovação tecnológica. Após passar pelo primeiro crivo, solicita-se o envio dos produtos ou protótipos para uma segunda fase de avaliação. O processo é finalizado com a definição de 1ㅇ, 2ㅇ e 3일 lugares de cada categoria e com a distribuição de menções honrosas para projetos de destaque. O resultado vem a público por meio de exposição no Museu da Casa Brasileira, instituição da Secretaria da Cultura do Estado de São Paulo.

Mas como esses artefatos são tratados nos eventos expositivos em questão? Quais são as estratégias expográficas de uma realização que é referência no país?

Este artigo apresenta uma análise da mostra do 29 Prêmio Design, ocorrida entre 26 de novembro de 2015 e 31 de janeiro de 2016. Por meio de abordagem exploratória-descritiva atentou-se para as características materiais percebidas em visita específica, realizada em 28 de janeiro de 2016. Imagens, textos, disposição dos artefatos, cenografia, trajetória de visitação são alguns dos aspectos remarcados. Estratégias expográficas foram identificadas, sendo suas potencialidades e limites discutidos por meio da articulação de noções como "cultura pública" e "abordagem interocular", propostos pelo antropólogo Arjun Appadurai (2007). Dedicando-se a estudar os museus da Índia, Appadurai julga que a renovação desse tipo de instituição localiza-se na aproximação entre educação formal e entretenimento, entre arte e cultura de massa, entre salas de museus, feiras e mercados.

Essa perspectiva permite pensar sobre o fato de a presença de artefatos de design contemporâneo em salas de um museu favorecer a articulação simbólica entre difentes dimensões culturais. Contudo, de maneira predominante, as estratégias expográficas identificadas na mostra da 29ạ edição do Prêmio Design Museu da Casa Brasileira investem em apresentar artefatos de uso como obras de arte.

\section{DESENVOLVIMENTO}

\subsection{Exposições de design em foco}

Recentemente, Ethel Leon, doutora em História e Fundamentos da Arquitetura e do Urbanismo pela Faculdade de Arquitetura e Urbanismo da Universidade de São 
Paulo defendeu a tese Design em exposição: o design no Museu de Arte Moderna do Rio de Janeiro (1968-1978), na Federação das Indústrias de São Paulo (1978-1984) e no Museu da Casa Brasileira (1986-2002). Em seu trabalho Ethel Leon avalia exposições de design atreladas a iniciativas institucionais, articulando um quadro referencial que envolve a História Cultural (Roger Chartier), a Sociologia (Pierre Bourdieu) e questões sobre valor e uso nas exposições (Krzysztoff Pomian). Estuda documentos coletados em acervos mantidos pelas instituições promotoras e conclui que as concepções de design apresentadas pelas narrativas das exposições realizadas confina o design brasileiro ao mundo doméstico de elite.

O Museu da Casa Brasileira, ainda segundo a pesquisadora, vem construindo a imagem de museu de arquitetura e design por meio de exposições efêmeras, especialmente, as mostras anuais do Prêmio Design. As edições do Prêmio acalentam "a cultura do designer/autor" tornando-se referência interna para os profissionais da área, sem demonstrar preocupação com o sentido da atividade para um público mais amplo. Segundo ela, ao manter um prêmio consagrador que cumpre a função de selo comercial e ao dedicar salas com mostras de indivíduos/autores, o Museu promove a "artificação de objetos de design". Citando Roberta Shapiro, Ethel Leon explica que

a artificação designa o processo de transformação da não arte em arte, resultado de um complexo trabalho que engendra uma mudança de definição e de estatuto das pessoas, dos objetos e das atividades. [...] a artificação é o resultado do conjunto de operações, práticas e simbólicas, organizacionais e discursivas por meio das quais os atores se põem de acordo para considerar um objeto ou uma atividade como da arte." (SCHAPIRO apud LEON, 2012, p.166)

A pesquisadora avalia que a ênfase no processo de artificação não permite que os encargos de uma instituição de exposições de design possam realizar compromissos públicos importantes, atrelados a "objetos de escalas e objetivos mais generosos". 0 modo como o Museu da Casa Brasileira posiciona-se quanto à difusão de conceitos e apresentação de artefatos de design não contribui para que o design brasileiro construa ambições maiores do que servir ao mercado de consumo. Segundo ela, "A autonomia do design, que, como toda autonomia de campo é relativa, só pode ser construída a partir de prática e reflexão conjuntas, que responda a questões sociais amplas e não apenas ao mercado." (LEON, 2013, p. 180)

O atual diretor técnico do MCB, Giancarlo Latorraca, considera a atuação da instituição de outra maneira. Em suas Anotações para um museu de arquitetura $e$ design brasileiro (2001), que compõe a coletânea Museus: o que são, para que servem? (publicada pela Secretaria Estadual de Museus-SP) afirma que a construção de acervo e promoção de exposições realizadas pelo MCB buscaria ligar-se à ideia do objeto brasileiro, escapando da folclorização ou valorização estética. Segundo ele,

A compreensão das disciplinas ligadas ao design e à arquitetura neste museu difere da visão inicial presente nos museus de arte modernos e de origem no modelo americano do pós-guerra, que incorporaram esses conteúdos vislumbrando aspectos mais formalistas e estetizantes, como arte ou expressão técnica de reconhecido valor artístico. Sua matriz de viés antropológico inicia uma leitura histórica de visão ampla, que deve transcender a representação do objeto 
único, apresentado como ideia isolada de projeto e fabricação. De certa forma contra o ícone de design consagrado, (...). O foco passa a recair sobre os arranjos entre objetos, seus contextos, usos e simbologias coletivas." (LATORRACA, 2011, p. 84)

Afirma ainda que a proposta de museus como o MCB é ir "contra o ícone de design consagrado". O desafio maior é "libertar o design de sua 'aura'" e contribuir de forma significativa para a "incorporação consciente do design em nossas vidas.".

Giancarlo Latorraca assume o cargo de diretor técnico em 2008, junto com Miriam Lerner. Segundo ele, a manutenção da trajetória do Prêmio Design era considerada uma tarefa de extrema relevância. Logo no início de sua gestão deu-se início a

uma série de discussões internas, envolvendo membros das comissões julgadoras anteriores, funcionários do museu, embora do conselho de administração e designers, no intuito de identificar oportunidades de atuação. (...) Assim, foram alterados o regulamento, os critérios de avaliação e a estrutura das categorias, cujas principais mudanças foram a inclusão das modalidades protótipos e trabalhos escritos não publicados. Os processos de inscrição e análise durante a primeira fase foram informatizados. Ao cartaz buscou-se devolver a força e destaque enquanto peça gráfica. Foram estabelecidas novas parcerias e estratégias de divulgação. 0 mote, sempre o mesmo, promover as alterações necessárias para garantir a manutenção da ideia visionária que embasou sua concepção original. (LATORRACA, 2011, p. 8)

Mas e quanto às mostras do Prêmio Design? O uso das salas, a definição de trajetórias possíveis, o modo de apresentação dos produtos, a relação dos artefatos e os visitantes da exposição, não foram aspectos mencionados no projeto de manutenção do evento descrito pelo diretor na introdução do livro-catálogo 21 a $a$ 25o Prêmio Design Museu da Casa Brasileira (2011).

No trabalho de Ethel Leon aspectos como esses são também ignorados. A abordagem da ideologia das exposições do Prêmio Design dá-se de maneira abstrata. Sua crítica quanto às mostras promovidas não se constrói a partir do exame efetivo da expografia. O leitor de sua tese não tem subsídios para compreender o processo de artificação indicado pela autora. Muito provavelmente, ela conta com a memória de um receptor iniciado que acompanha os eventos ano a ano. Somente acessando lembranças será possível vislumbrar como os objetos de design são transformados em objetos de arte, pois não há sequer uma descrição, uma imagem de exposição do Prêmio Design como ilustração.

Este ensaio constitui-se na fissura aberta pela pouca atenção dada à potencialidade da expografia para materializar ideias sobre o design. Pretende ressaltar que uma reflexão crítica sobre possibilidades e limites do Prêmio Design seria enriquecida pela consideração não somente sobre quais são os projetos selecionados, mas também sobre como os artefatos de design são expostos no museu, em interação com uma audiência mais ampla. Por esse motivo, o seu foco é descrever uma visita à mostra recente do Prêmio Design, buscando perceber em suas propriedades concretas indícios de outras possibilidades conceituais. 


\subsection{Estratégias expográficas da mostra do 29 Prêmio MCB}

O Prêmio Design Museu da Casa Brasileira apresenta fases distintas como inscrição, seleção e definição dos projetos laureados. A exposição é o momento em que os resultados do processo são apresentados de maneira a valorizar os projetos premiados e o processo de julgamento realizado. Contudo, ao visitar a mostra e atentar para aspectos de sua expografia foi possível reconhecer que o modo como os artefatos foram expostos produz sentidos que não seriam construídos por nenhuma outra etapa do concurso.

A abertura da exposição foi em 26 de novembro de 2015 e a visita aqui descrita deu-se no dia 28 de janeiro de 2016, dois dias antes de seu encerramento. 0 espaço expositivo foi percorrido por três vezes consecutivas. Inicialmente, foram contempladas as características visuais dos objetos, sem dar muita atenção às informações textuais. Nesse momento, a preocupação foi identificar e seguir a trajetória claramente manifesta. Na segunda rodada, além de contemplar os objetos e repetir o trajeto, ateve-se aos textos dos jurados e das etiquetas de cada produto, realizando-se registros fotográficos. Por fim, na última exploração, um vídeo de tomada contínua foi feito, respeitando a trajetória seguidamente realizada (figura 1).

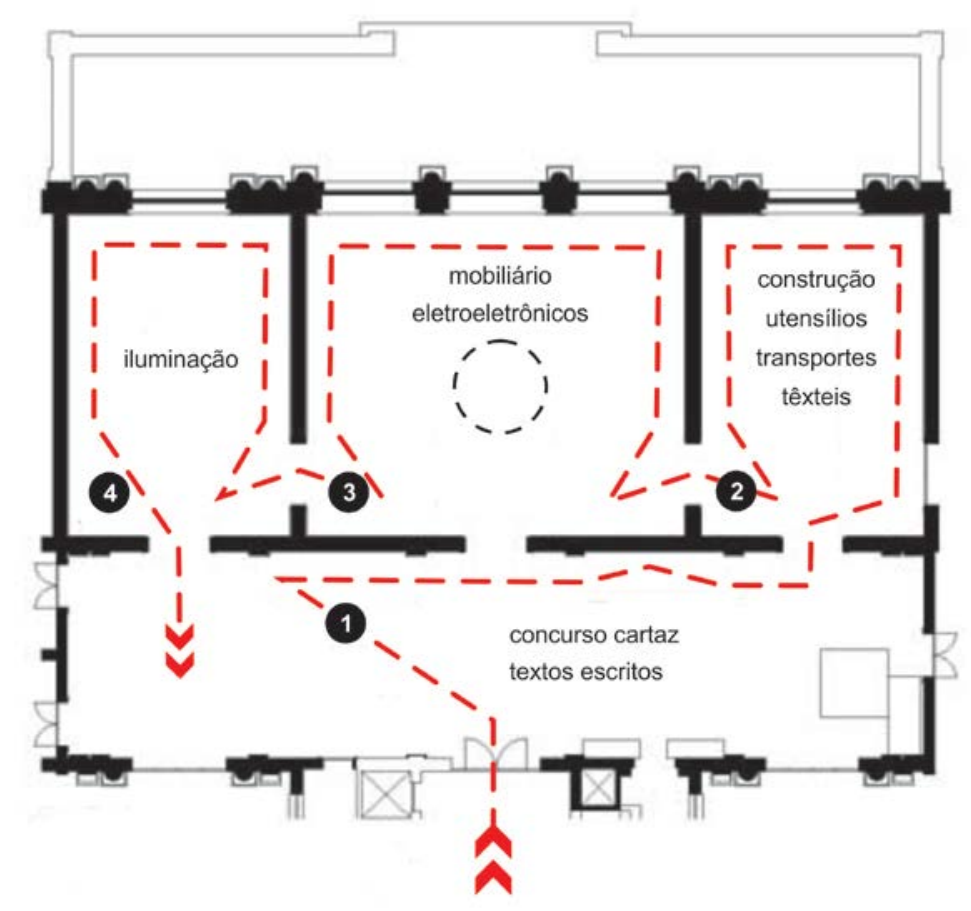

FIGURA 1 - Trajetória realizada na mostra do 29 Prêmio Design MCB. Fonte: Elaborado pelos autores.

Assim como em edições anteriores, a mostra do Prêmio Design foi disposta de modo a ocupar o hall de entrada e as três salas frontais do Museu da Casa Brasileira, locais de fácil acesso aos visitantes. Através da porta principal do Museu era possível visualizar uma grande imagem marcando a identidade visual do evento e o início da exposição.

No hall, à esquerda, encontrava-se a área dedicada ao "concurso do cartaz", constando texto dos jurados fixado na parede e os cartazes finalistas distribuídos lado a lado. Ainda no mesmo espaço, à direita, encontrava-se a seção dos "trabalhos 
escritos" premiados. Além do texto assinado pela coordenadora da comissão julgadora na parede, havia um conjunto de móveis que permitia que o visitante sentasse e apreciasse os livros e versões impressas de teses e dissertações acadêmicas.

A continuidade da visita poderia acontecer a partir de três possibilidades, pois havia três portas disponíveis. Contudo, o sentido de leitura favorecia a indicação da terceira delas como caminho lógico. O reforço da trajetória preferencial deu-se também por meio de estrutura posicionada perpendicularmente, com textura e cor diferenciada. Ademais, a estrutura ostentava a palavra "produtos" com as mesmas características visuais dos títulos que indicavam as duas seções anteriores, "concurso do cartaz" e "trabalhos escritos".

A primeira sala abrigava os produtos das categorias "construção", "utensílios", "transportes" e "têxteis". Havia uma diversidade de produtos alinhados de modo regular, acompanhados de etiquetas indicando as especificidades de cada um. A etiqueta apresentava a classificação (10 lugar, 2ㅇ lugar, 3ㅇ lugar, menção honrosa, finalista, finalista protótipo) e dados básicos do produto (nome, autor ou autores, cidade de origem, produção). Ostentava também breve texto sobre o projeto e o reforço de seu pertencimento a categoria específica. (quadro 1)
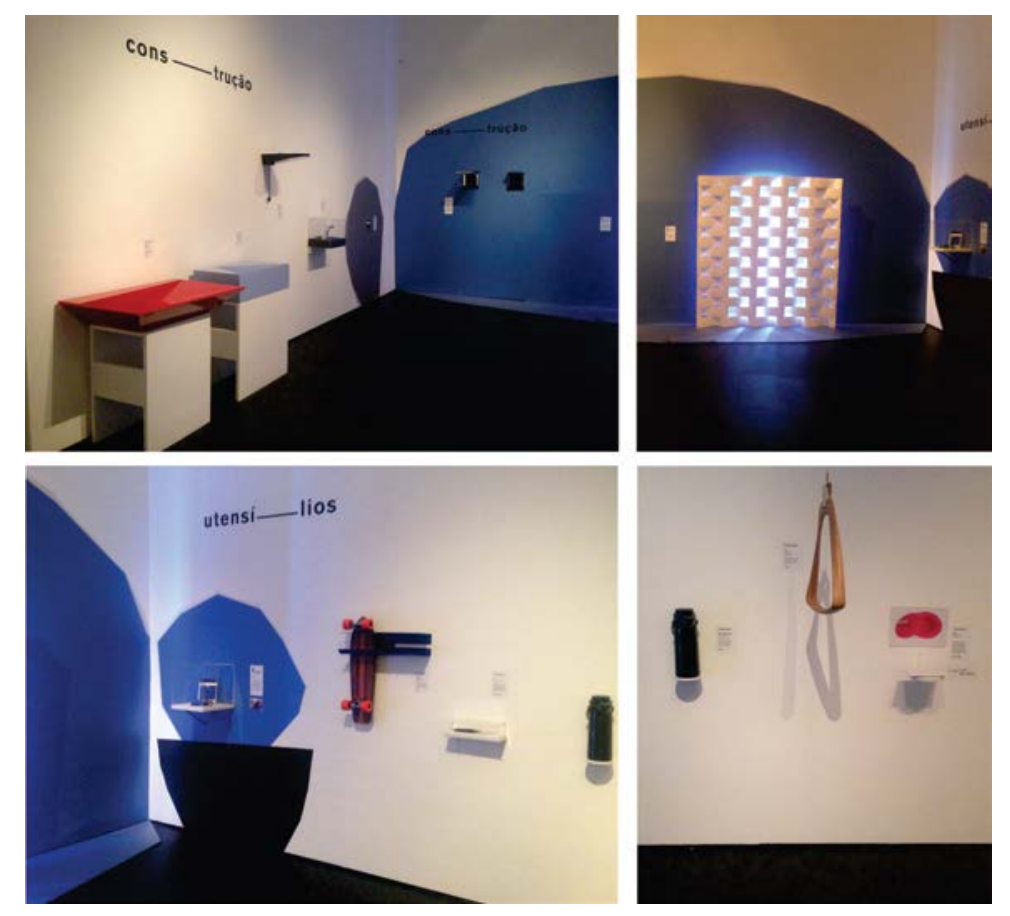

QUADRO 1 - Primeira sala da mostra do 29 Prêmio Design MCB. Fonte: Elaborado pelos autores.

A segunda sala configurava-se de modo semelhante, mas abrigava somente duas categorias de produtos: "eletroeletrônicos" e "mobiliário". A proporção da ocupação era desigual, sendo a quantidade de móveis superior. Enquanto as duas primeiras salas apresentavam uma luminosidade análoga, certa obscuridade diferenciava a última delas. Oferecia, portanto, as condições essenciais para que os produtos da categoria "iluminação" emitissem luz, construindo efeitos singulares.

Como pinturas, a grande maioria dos produtos estava presa à parede. A posição no suporte, em contrapartida, incitava uma experiência de uso. Na primeira sala, os produtos da categoria "construção" e "utensílios" estavam todos fixados de acordo 
com a interação humana prevista: os chuveiros da linha Acqua, acima da cabeça, a válvula de descarga Select, na altura do tronco. Remetiam ao modo como esse tipo de objeto é instalado em mostruários de lojas especializadas, disponíveis ao toque e à visão aproximada. Contudo, formas ovais azuladas, com textura reticulada, em consonância com os elementos visuais do cartaz premiado, funcionavam como uma espécie de moldura. Próximo a esses objetos estava um pequeno aquário de vidro, também fixado na parede. Dentro dele, a torneira eletrônica Ecotron era apresentada como uma escultura, isolada e inacessível à manipulação.

Ainda nessa sala, entre outros produtos da categoria "utensílios", a garrafa térmica Genesis escapava das ovais coloridas e destacava-se sobre a parede totalmente branca. Era sustentada por um suporte diminuto, circular, exatamente nas dimensões de sua base. O objeto parecia quase flutuar, porém, mostrava-se muito frágil e suscetível à queda. Ao seu lado, havia alguns protótipos fixados na parede, de maneira muito semelhante, acompanhados da frase: "por favor, não toque".

Havia uma maior ênfase cenográfica na segunda sala, mais ampla que as demais, dedicada às categorias "eletroeletrônicos" e "mobiliário". As formas ovais, já indicadas, configuravam uma espécie de pedestal ou palco tanto para a Espreguiçadeira Adapta e a poltrona Kei (à direita), quanto para o banco Frida e a mesa Twist (à esquerda). O mesmo recurso foi utilizado para delimitar a área central ocupada pelo banco Ratoeira, o 10 lugar da categoria "mobiliário". O móvel podia ser visualizado em 360 graus, uma condição excepcional, pois a distribuição dos demais objetos era igualmente rente às paredes. Nessa condição encontrava-se mais um exemplar do mesmo banco premiado, que ostentava logo abaixo de sua etiqueta de identificação a palavra "experimente". A maioria das cadeiras apresentadas no espaço indicava a mesma permissão. (quadro 2)
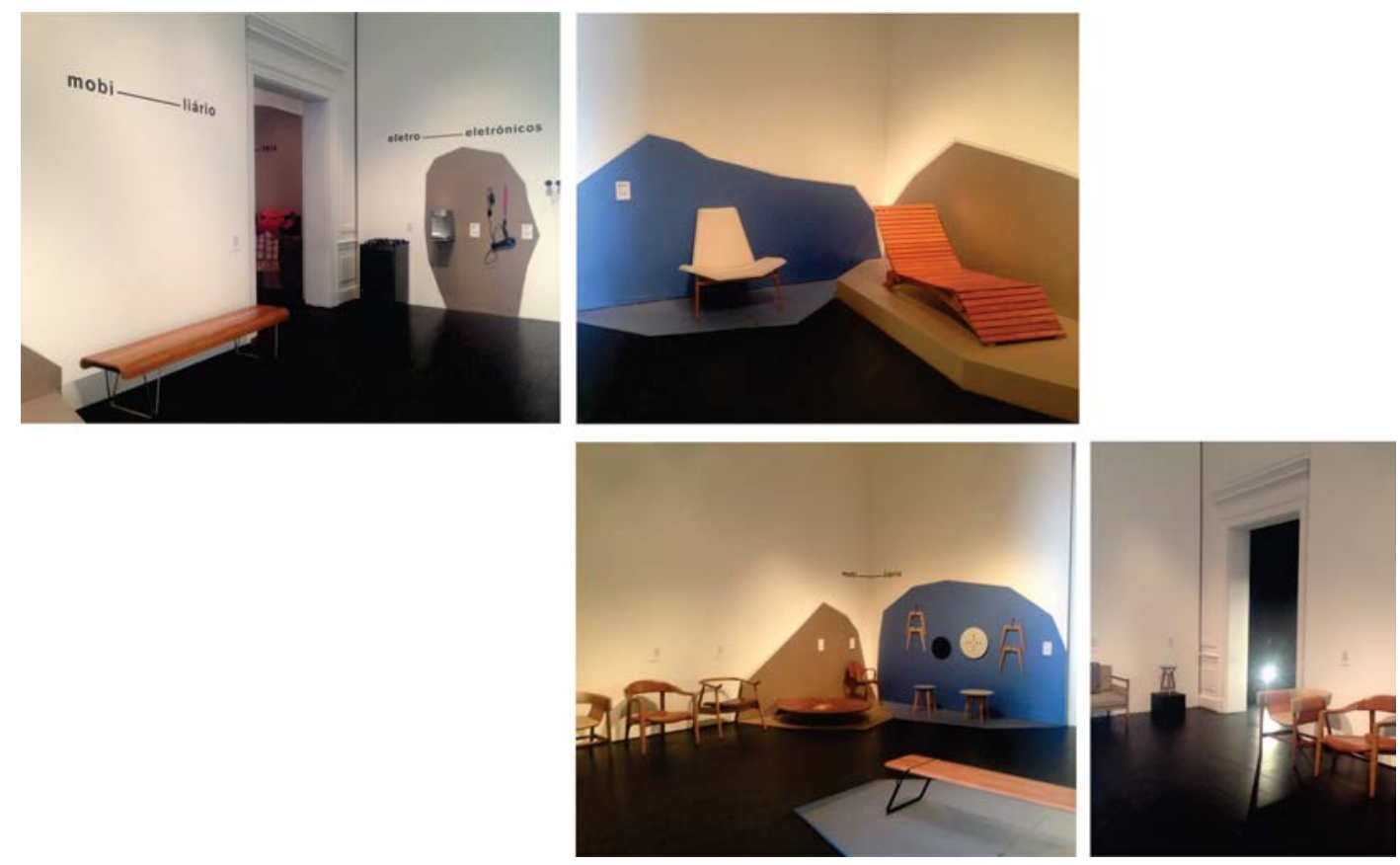

QUADRO 2 - Segunda sala da mostra do 29ㅇ Prêmio Design MCB. Elaborado pelos autores.

A ação, todavia, era vigiada por uma pessoa que, durante a toda visita não atuou como monitora ou guia, mas como guardiã da integridade física dos objetos. Chamou a 
atenção de um casal que tocava um produto interditado e mantinha um olhar atento sobre as pessoas que experimentavam as cadeiras disponíveis.

Na última sala, os produtos pertenciam somente à categoria "iluminação" e a possibilidade de experimentação não foi mais indicada ao lado das etiquetas dos produtos. As luminárias de mesa, como a Plamp $Z$ e a Ani, eram sustentadas por pequenas prateleiras, semelhantes às estruturas utilizadas na primeira sala. Luminárias de chão como a Plano e a Anatole eram também emolduradas pelas formas ovais já referenciadas. Os recursos cenográficos foram explorados inclusive como representações de possíveis projeções de luz, criando ilusões e intensificando efeitos.

Sobre a luminária Ísis, 10 lugar da categoria "iluminação", o breve texto da etiqueta ressaltava: "encanta pelo equilíbrio em balanço que concretiza solução ao mesmo tempo sintética e singular. Sua aparente simplicidade, contrasta com a elegante eficiência (...)". Grande parte dos demais textos apresentava equivalente cunho qualitativo:

O produto b.blend, alia de forma única e inovadora, a facilidade e praticidade do preparo de uma grande variedade de bebidas, antes oferecido em equipamentos diferentes. Com seu design ao mesmo tempo simples e sofisticado, o produto é atraente pelo seu acabamento diferenciado e oferece uma usabilidade intuitiva, facilitada pela eletrônica embarcada. Versátil, pode ser instalado em diversos ambientes, tanto residenciais como empresariais. (29을 PRÊMIO DESIGN MCB, 2015, p. 39).

Outros textos, entretanto, eram mais curtos e descritivos: "Ducha com controle eletrônico de potência ao alcance das mãos, com mostrador digital de temperatura e quantidade de água consumida durante o banho." "Poltrona fabricada com técnicas tradicionais de marcenaria, possui estrutura em freijó maciço, assento e laminado curvo e estofado em couro natural."

Já os textos dos coordenadores das comissões julgadoras, presentes em cada seção da exposição, foram dedicados a esclarecer os critérios em jogo, justificando a presença dos objetos na exposição. Segundo Gustavo Piqueira, "A virtude mais óbvia do cartaz vencedor, de Ana Costa, é aquela obrigatória a todo bom cartaz: atrair o olhar." Para Priscila Lena Farias, os trabalhos escritos premiados correspondiam a "Textos que merecem ser lidos em formatos que merecem ser vistos, e que devem ajudar a compreender o campo e estimular novas pesquisas e reflexões sobre ele". (29ㅇ PRÊMIO DESIGN MCB, 2015, p. 11). Artur Grisanti Mausbach destaca que "Os critérios de avaliação dos produtos e protótipos inscritos no prêmio, além de considerarem originalidade, inovação tecnológica e concepção formal, colocam questões de universalidade e sustentabilidade hoje como imprescindíveis." (29o PRÊMIO DESIGN MCB, 2015, p. 28)

\subsection{Entre a contemplação e a crítica}

A exposição do Prêmio Design produziu mais do que um retrato do concurso. Segundo Cristina Freire (2011, p. 70), "a relação criada entre as obras expostas num determinado lugar engendra um discurso". Assim, "expor objetos é propor questões, produzir sentidos." O espaço construído pela mostra corrobora uma condição de autonomia, oferecendo aos visitantes objetos que confrontam a banalidade tornando- 
se torneira-escultura, banco-pintura, luminária-instalação. Produz sentidos para os objetos que não estavam nas descrições ou inscritas em sua materialidade, mas que configuram decisiva alteração de status.

Nesse sentido, o processo de artificação apontado por Ethel Leon pode ser confirmado. Entretanto, o mesmo não se dá de modo homogêneo. Alguns produtos estão ao alcance das mãos e em relações espaciais semelhantes às situações de uso mais comuns. Alguns podem ser efetivamente "experimentados". A mostra visitada, portanto, inscreve tensões entre modos de expor objetos em lojas e supermercados e os modelos tradicionais de exposição. Como estratégia discursiva, a expografia, vivenciada e descrita aqui, indica uma minoritária negociação entre os limites simbólicos entre artefatos utilitários e obras de arte. Essa negociação, apesar de escasa, serve como ponto de partida para se pensar sobre novas relações entre a inquietação de Ethel Leon e as aspirações de Giancarlo Latorraca.

A questão aqui delineada é provocada pela perspectiva de Arjun Appadurai, antropólogo e professor de Mídia, Cultura e Comunicação na New York University. Em seu texto Museus são bons para pensar: o patrimônio em cena na Índia (2007), o pesquisador destaca que na Europa e nos Estados Unidos os museus investiram em "uma separação entre arte e ciência e entre festividade e comércio." Devido ao singular processo de modernização da Índia, as especializações e separações dos colonizadores não fizeram, e não fazem sentido. Os museus, portanto, "fazem parte de uma preocupação generalizada, provocada pelos meios de comunicação de massa, com o patrimônio e com uma rica abordagem visual dos espetáculos." Devem ser vistos em articulação com exposições de todos os tipos, e como parte de um mundo cosmopolita. (APPADURAI, 2007, p. 17-18)

O pesquisador ressalta que a fresca renovação pós-colonial dos museus em seu país de origem relaciona-se com a potência de uma "abordagem interocular". Esta abordagem considera que o "olhar público" é afetado em algum grau pelas experiências que os espectadores tem em outros espaços culturais. Desse modo, o museu faz parte de um complexo significativo denominado por ele como "cultura pública".

Os espectadores não chegam aos museus como 'vazios culturais'. Eles vêm sob a forma de pessoas que assistiram a filmes com temas nacionalistas, seriados de televisão com narrativas e imagens nacionalistas e mitológicas e leram jornais e revistas que também constroem e visualizam os heróis e eventos grandiosos da história e da mitologia indianas. (...) a visitação a museus não está acentuadamente separada de outras formas de lazer e de aprendizado; e a ideia de documentação especializada e de certificados na interpretação de objetos não descolou a compreensão de que grupos espectadores têm o direito de formular suas próprias interpretações. (APPADURAI, 2007, p. 20-21)

A partir do ponto desse ponto de vista, as perguntas iniciais e seminais deste artigo foram reescritas: Como seria a visita à mostra da 29a edição do Prêmio Design MCB se os artefatos fossem menos valorizados como objetos a serem contemplados? Se mais produtos presentes fossem "experimentáveis"? Se houvesse condições para que o visitante pudesse também criticar os objetos, a partir das suas experiências 
como usuário, como consumidor? Muito provavelmente, seria um espaço para pensar o design em relação com outras dimensões da cultura pública no Brasil contemporâneo.

\section{CONSIDERAÇÕES FINAIS}

Este artigo não apresentou um exame rigoroso da mostra do 29 Prêmio Design $\mathrm{MCB}$, mas partiu do pressuposto que abordagens teóricas abstratas sobre exposições de design abrem pouca margem para reflexões críticas. Não se obteve uma lista de requisitos para novas exposições, mas deu-se ênfase na importância de se explicitar estratégias discursivas expográficas naturalmente reproduzidas.

As motivações dos caminhos tomados pela expografia contemplada também não foram enfocadas. Destacou-se, entretanto, que ao adotar o ponto de vista da recepção e da relação das instituições museais com outras esferas culturais é possível reposicionar questionamentos acadêmicos já feitos sobre o tema.

\section{REFERÊNCIAS}

29 PRÊMIO DESIGN MCB. (Catálogo da mostra). São Paulo: Museu da Casa Brasileira, 2015.

APPADURAI, Arjun. Museus são bons para pensar: o patrimônio em cena na Índia. In: MUSAS - Revista Brasileira de Museus e Museologia, n. 3, 2007. Rio de Janeiro: Instituto do Patrimônio Histórico e Artístico Nacional, Departamento de Museus e Centros Culturais, 2004. p. 10-26.

BORGES, Adélia. Prêmio Design: 1986-1996. São Paulo: Museu da Casa Brasileira, 1996.

FREIRE, Cristina. Dos museus e das exposições: por uma breve arqueologia do olhar. In: SECRETARIA ESTADUAL DE MUSEUS - SISEM SP (org). Museus: o que são, para que servem?. Secretaria de Estado da Cultura de São Paulo. São Paulo, 2011. p. 70-78.

LATORRACA, Giancarlo. Anotações para um museu de arquitetura e design brasileiro. In: SECRETARIA ESTADUAL DE MUSEUS - SISEM SP (org). Museus: o que são, para que servem?. Secretaria de Estado da Cultura de São Paulo. São Paulo, 2011. p. 80-86.

LATORRACA, Giancarlo; LERNER, Miriam. Introdução. In: GIORGI JUNIOR, Giorgio. 21 ao 250 Prêmio Design Museu da Casa Brasileira. São Paulo: Museu da Casa Brasileira, 2011. p. 7-8.

LEON, Ethel. Museu da Casa Brasileira: design no processo de artificação. In:

Design em exposição: o design no Museu de Arte Moderna do Rio de Janeiro (19681978), na Federação das Indústrias de São Paulo (1978-1984) e no Museu da Casa Brasileira (1986-2002). Tese apresentada à Faculdade de Arquitetura e Urbanismo da Universidade de São Paulo para obtenção do título de doutora em História e Fundamentos da Arquitetura e do Urbanismo. São Paulo, 2012. p. 139-171.

PRÊMIO DESIGN MCB. Disponível em http://www.mcb.org.br/pt-BR/premiomcb/sobre. Acessado em 26 mai 2016. 